(2) Open Access Full Text Article

\title{
Comparison of dexmedetomidine and fentanyl as local anesthetic adjuvants in spinal anesthesia: a systematic review and meta-analysis of randomized controlled trials
}

This article was published in the following Dove Press journal:

Drug Design, Development and Therapy

\section{ShuJun Sun' \\ JiaMei Wang ${ }^{2}$ \\ $\mathrm{NaRen} \mathrm{Bao}^{\prime}$ \\ Ying Chen' \\ Jun Wang'}

'Department of Anesthesiology, First Affiliated Hospital, China Medical University, Shenyang, Liaoning, ${ }^{2}$ College of Life and Health Sciences, Northeastern University, Shenyang, Liaoning, China
Correspondence: Jun Wang

First Affiliated Hospital of China Medical University, 155 Nanjing Street, Heping District, Shenyang, Liaoning Province, China

Tel +86I584037 7700

Email wangjuncmu@hotmail.com
Purpose: To compare the effects of dexmedetomidine (Dex) and fentanyl as adjuvants to local anesthetics in spinal anesthesia.

Methods: Two researchers independently searched the PUBMED, EMBASE, Cochrane library, and CBM for randomized controlled trials comparing the effects of Dex and fentanyl as adjuvants to local anesthetics for intrathecal injection.

Results: A total of 639 patients from nine studies were included in this meta-analysis. The results showed that Dex resulted in statistically significant longer duration of stable sensory block (mean difference $[\mathrm{MD}]=27.12 ; 95 \%$ confidence interval $[\mathrm{CI}][9.89,44.34], P<0.01$, $I^{2}=97 \%$ ), sensory block (standardized mean difference $[\mathrm{SMD}]=3.81 ; 95 \%$ CI $[2.35,5.27]$, $P<0.01, I^{2}=97 \%$ ), motor block (SMD =3.64; 95\% CI [2.19, 5.08], $P<0.01, I^{2}=97 \%$ ), and pain free period $\left(\mathrm{SMD}=2.98 ; 95 \% \mathrm{CI}[1.69,4.27], P<0.01, I^{2}=96 \%\right.$ ); reducing the incidence of pruritus (relative risk $[\mathrm{RR}]=0.15 ; 95 \% \mathrm{CI}[0.06,0.39], P<0.01, I^{2}=0 \%$ ) compared with fentanyl. However, the onset of sensory and motor block, the time to peak sensory level, and the incidence of hypotension and bradycardia, and the side effects (nausea, vomiting, shivering and respiratory depression) were not significantly different between Dex and fentanyl.

Conclusion: Compared to fentanyl, Dex as local anesthetics adjuvant in spinal anesthesia prolonged the duration of spinal anesthesia, improved postoperative analgesia, reduced the incidence of pruritus, and did not increase the incidence of hypotension and bradycardia.

Keywords: dexmedetomidine, fentanyl, meta-analysis, spinal anesthesia

\section{Introduction}

Spinal anesthesia is a safe and reliable method of anesthesia for abdominal and lower limb surgery, with the advantages of rapid onset of action, economical and easy to administer, and a relatively low side effects rate and shorter post-anesthesia care unit stay. ${ }^{1,2}$ However, these advantages may be offset by the limited duration of action, or an increased likelihood of motor power recovery delay, thus delaying ambulation and prolonged hospital stay., In order to improve the quality of blockage and prolong the duration of analgesia, and reduce the required dose of local anesthetics, thereby reducing the incidence of side effects caused by the use of high-dose local anesthetics, such as late and severe bradycardias, hypotension, nausea, and vomiting, appropriate adjuvants are commonly used for intrathecal local anesthetics. ${ }^{5,6}$

It has been found that many drugs, such as opioids (morphine, fentanyl, and sufentanil), $\alpha_{2}$ adrenergic agonists (dexmedetomidine [Dex] and clonidine), magnesium 
sulfate, neostigmine, ketamine, and midazolam, can be used as adjuvants for intrathecal local anesthetics to improve the quality of spinal anesthesia. ${ }^{7}$ However, the opioids and $\alpha_{2}$ adrenergic agonists are more commonly used as adjuvants in clinical practice. During the intrathecal or epidural administration, fentanyl has a more rapid onset and shorter duration of action than morphine, which has become one of the most commonly used neuraxial opioids. Dex, a selective $\alpha_{2}$ adrenergic receptor agonist, has been shown to be a better adjuvant of local anesthetics for neuraxial blocks, ${ }^{8-10}$ although clonidine is the first clinically used intrathecal $\alpha_{2}$-adrenoreceptor agonist. ${ }^{11}$

There is limited research of multi-center large sample randomized controlled trials (RCTs) to evaluate the advantages or disadvantages between Dex and fentanyl as local anesthetics adjuvants in spinal anesthesia. Moreover, some of their results were disputable. Therefore, the present metaanalysis was performed to confirm their conclusions using a large sample size.

\section{Methods}

\section{Searching strategy}

Two researchers searched PUBMED, EMBASE, Cochrane library, and CBM independently. The mesh and keywords used for the searches included: "Dex", "Fentanyl", "Anesthesia, Spinal", "Injections, Spinal", "Bupivacaine", "ropivacaine", and "Randomized controlled trial". The latest search was done on May 20, 2017. Furthermore, the investigators scanned references of these articles to prevent missing articles.

\section{Study inclusion criteria}

The trials included in our meta-analysis: adult patients (aged $\geq 18$ years) undergoing spinal anesthesia were randomly assigned to groups (at least two groups), including Dex alone as an adjuvant to local anesthetics and fentanyl alone as an adjuvant to local anesthetics. Children, diabetics, drug addicts, and those with contraindications to spinal block were excluded.

\section{Data extraction}

\section{Data extraction and study characteristics}

Two reviewers independently selected eligible studies, using a standard data collection table to extract data and record the trial characteristics. For each study, the following information was collected: the first author's name, date of publication, number of patients, peak sensory block level, types of surgery, the drugs and total volume for spinal anesthesia (Table 1).

- The onset of sensory block: the time between intrathecal injection to the T12 or higher dermatome.

- The onset of motor block: the time between intrathecal injection to the modified Bromage score (modified Bromage scale: $0=$ no motor loss, $1=$ inability to flex the hip, $2=$ inability to flex the knee, $3=$ inability to flex the ankle) $)^{12}$ of 1 or higher score.

- Time to peak sensory level: the time to the highest dermatomal level of sensory block.

- Duration of stable sensory block: the time of regression to T10 or two dermatome segments from the maximum sensory block level.

- Duration of sensory block: the time of regression to S1 from the maximum sensory block level.

- Duration of motor block: the time of regression to modified Bromage score of 0 .

- Pain free period: the time from intrathecal injection to the first time of complaint about pain or rescue analgesia.

- Side effects: the occurrence of nausea, vomiting, shivering or respiratory depression.

Table I Characteristics of the included studies

\begin{tabular}{|c|c|c|c|c|c|c|c|}
\hline Study & Year & $\begin{array}{l}\text { Application } \\
(\mu \mathrm{g})\end{array}$ & $\begin{array}{l}\text { Sample } \\
\text { size }\end{array}$ & $\begin{array}{l}\text { Local } \\
\text { anesthetics } \\
\text { (mg) }\end{array}$ & $\begin{array}{l}\text { Total } \\
\text { volume } \\
(\mathrm{mL})\end{array}$ & PSBL (D/F) & Operation \\
\hline Qi et $\mathrm{al}^{6}$ & 2016 & NS/D5/FI 5 & $36 / 36 / 36$ & Rop 7.5 & 2 & T 9.64 $\pm 2.31 / T 9.86 \pm 2.03 *$ & Hysteroscopic procedures \\
\hline Basuni and Ahmed Ezz ${ }^{12}$ & 2014 & D3/FIO & $30 / 30$ & Bup 4 & 3 & T8 (6-II)/T8 (5-II) & Knee arthroscopy \\
\hline Suresh and Prasad ${ }^{13}$ & 2016 & D5/F25 & $30 / 30$ & Bup 12.5 & 3 & T6 (4-8)/T8 (6-10)\# & Lower abdominal surgeries \\
\hline Li et al $^{14}$ & 2015 & NS/DI0/C75/FI5 & $2|/ 2| / 2|/ 2|$ & Bup 10 & 4 & T4 (44\%)/T4 (42\%) & Cesarean section \\
\hline Nayagam et al $^{15}$ & 2014 & D5/F25 & $75 / 75$ & Bup 4 & 1.6 & T4 (4\%)/T6 (9\%) & Lower abdominal surgeries \\
\hline Gupta et al ${ }^{16}$ & 2011 & D5/F25 & $30 / 30$ & Bup 12.5 & 3 & T5 (4-8)/T6 (4-7)\# & Lower abdominal surgeries \\
\hline $\mathrm{Al}-\mathrm{Ghanem}$ et $\mathrm{al}^{17}$ & 2009 & D5/F25 & $38 / 38$ & Bup 10 & 2.5 & T6 (4-9)/T6 (3-8)" & Gynecological operation \\
\hline Sun et $\mathrm{al}^{18}$ & 2015 & NS/F25/DI0 & $30 / 30 / 30$ & Bup 10 & 3 & T4 (44\%)/T4 (40\%) & Cesarean section \\
\hline Mahendru et al ${ }^{19}$ & 2013 & NS/D5/C30/F25 & $30 / 30 / 30 / 30$ & Bup 12.5 & 3 & T6 (26.7\%)/T6 (I 3.3\%) ${ }^{\mathrm{a}}$ & Lower limb surgery \\
\hline
\end{tabular}

Notes: *Values are mean \pm standard deviation; \#data presented as median (range); ahighest sensory block level (\%).

Abbreviations: NS, saline; D, dexmedetomidine; F, fentanyl; Rop, ropivacaine; Bup, bupivacaine; C, clonidine; PSBL, peak sensory block level; T, thoracic level. 
The level of sensory block was tested bilaterally along the mid-clavicular lines by pin prick, while the motor block was assessed according to the modified Bromage scale.

\section{Assessment of risk of bias}

Two reviewers independently read and evaluated the methodological validity of all eligible studies using Cochrane Handbook v5.0.2. Any discrepancies were resolved through joint discussion, if necessary, a third researcher assisted in the decision. The following information was evaluated: random sequence generation, allocation concealment, blinding, incomplete outcome data, selective reporting, other bias, and each of them was graded as "high risk of bias", "uncertain risk of bias", "low risk of bias".

\section{Statistical analysis}

Quantitative analyses of all included RCTs were performed using Review Manager Software (version 5.3; Cochrane Collaboration, Copenhagen, Denmark). For dichotomous data, risk ratios with $95 \%$ confidence intervals (CIs) were computed using the Mantel-Haenszel method. When the measuring methods or indicator units used for the same interventions were different, or the mean difference (MD) between the different studies was large, the standardized mean difference (SMD) with 95\% CIs were calculated using the inverse variance method, otherwise the MD with 95\% CIs were calculated using the same method for continuous data. Meta-analysis was not performed for studies which did not report mean and SD or standard error of the mean (SEM). For heterogeneity analyses: data that were not significantly homogeneous $\left(I^{2}<50 \%\right)$ were analyzed with a fixed-effect model, otherwise, a random effect model was selected. When there was significant heterogeneity, we looked for possible causes of heterogeneity and performed subgroup analysis and sensitivity analysis to eliminate heterogeneity as much as possible.

\section{Results}

\section{Characteristics and risk of bias of eligible trials}

The flow chart of our study is shown in Figure 1. A total of nine RCTs were identified, involving 639 patients (320 received Dex and 319 fentanyl). The results of the included studies in the meta-analysis were shown in Tables 2 and 3. Eight studies ${ }^{12-19}$ used bupivacaine (two of these were low-dose bupivacaine) and one study ${ }^{6}$ used ropivacaine for spinal anesthesia. In these studies, five compared Dex with fentanyl, $, 12,13,18,19$ and the other two compared Dex with fentanyl and saline, ${ }^{16,17}$ the remaining two compared Dex

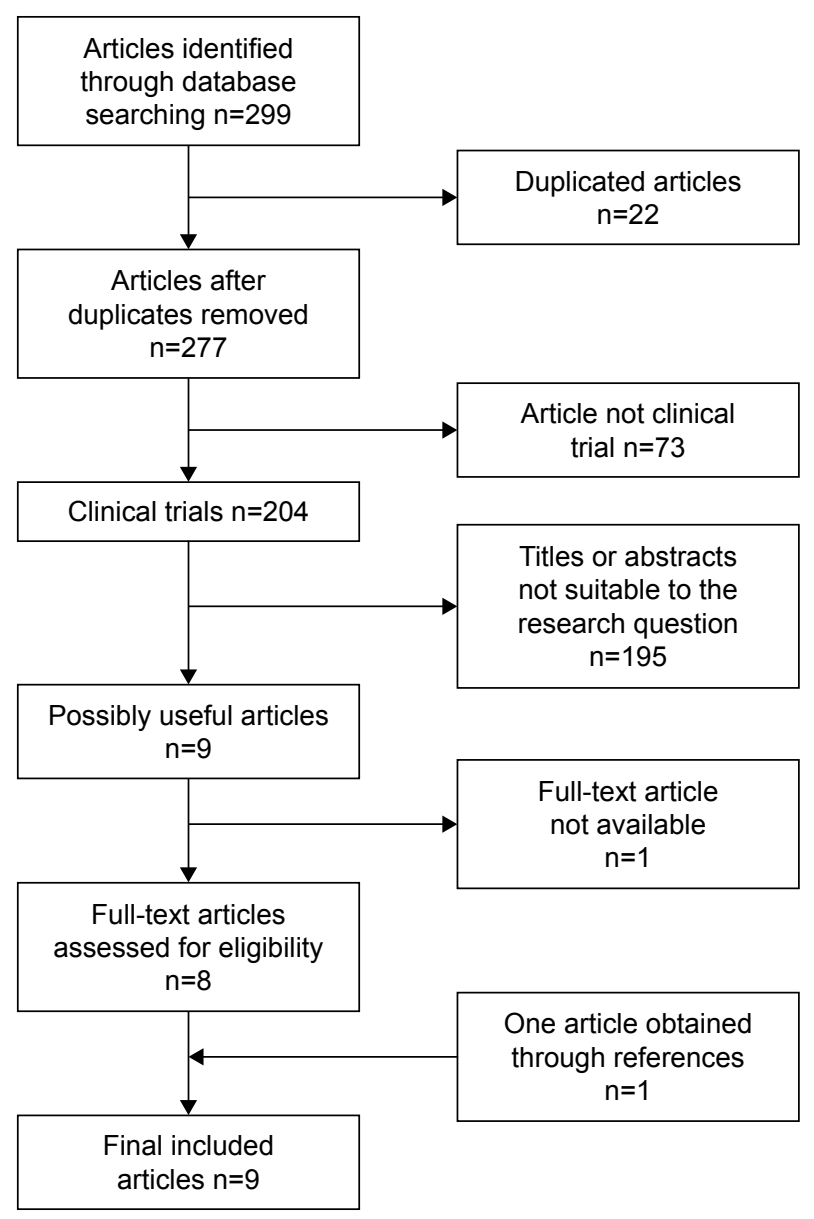

Figure I Flow chart for article selection in the meta-analysis.

with fentanyl and clonidine as well as saline. ${ }^{14,15}$ This metaanalysis only compares Dex with fentanyl, so we neglected clonidine and saline. The two reviewers were perfectly consistent on the risk of bias assessment, which showed that overall study quality was moderate. The risk-of-bias plot was created using the Review Manager 5.3 software, as shown in Figure 2.

\section{The onset of sensory block}

Six RCTs s2,14,15,17-19 reported the onset of sensory block, but two of them described only the mean of the index without the $\mathrm{SD}$, and the meta-analysis contained only the remaining four (Figure 3). The result of meta-analysis showed that there was no significant difference of the onset of sensory block between the two groups (MD $=-0.49 ; 95 \% \mathrm{CI}[-1.12,0.14]$, $\left.P>0.05, I^{2}=60 \%\right)$.

\section{The onset of motor block}

Eight studies ${ }^{6,12-14,16-19}$ compared the onset time of motor block of Dex and fentanyl as local anesthetic adjuvants for intrathecal injection. There was significant heterogeneity 
Table 2 The summary of results from individual studies

\begin{tabular}{|c|c|c|c|c|c|c|c|}
\hline Study & Year & Application & $\begin{array}{l}\text { The onset } \\
\text { of sensory } \\
\text { block (min)* }\end{array}$ & $\begin{array}{l}\text { The onset of } \\
\text { motor block } \\
(\mathrm{min})^{*}\end{array}$ & $\begin{array}{l}\text { Time to peak } \\
\text { sensory level } \\
(\mathrm{min})^{*}\end{array}$ & $\begin{array}{l}\text { Duration of } \\
\text { stable sensory } \\
\text { block (min)* }\end{array}$ & $\begin{array}{l}\text { Duration of } \\
\text { sensory } \\
\text { block (min)* }\end{array}$ \\
\hline \multirow[t]{2}{*}{ Qi et $\mathrm{al}^{6}$} & 2016 & $\mathrm{D}$ & & $20.42 \pm 5.25$ & $10.78 \pm 5.94$ & & $191.25 \pm 40.24$ \\
\hline & & $\mathrm{F}$ & & $18.94 \pm 4.45$ & $9.19 \pm 5.61$ & & $149.86 \pm 37.46$ \\
\hline \multirow[t]{2}{*}{ Basuni and Ahmed Ezz ${ }^{12}$} & 2014 & $\mathrm{D}$ & $3.9 \pm 1.2$ & $|4| \pm 2.3$. & $10.7 \pm 2.3$ & & $73.9 \pm 13.9$ \\
\hline & & $\mathrm{F}$ & $5.1 \pm 1.5$ & $|8.9 \pm 4|$. & $13.8 \pm 4.4$ & & $64.9 \pm 11.3$ \\
\hline \multirow[t]{2}{*}{ Suresh and Prasad ${ }^{13}$} & 2016 & $\mathrm{D}$ & & $5.71 \pm 1.369$ & $6.37 \pm 1.06$ & $110.33 \pm 11.54$ & $453.67 \pm 23.26$ \\
\hline & & $\mathrm{F}$ & & $5.4 I \pm I .69$ & $6.52 \pm 1.90$ & $81.50 \pm 15.6$ & $180.70 \pm 18$ \\
\hline \multirow[t]{2}{*}{ Li et a $\left.\right|^{14}$} & 2015 & $\mathrm{D}$ & & $7.2 \pm 2.25$ & $8.10 \pm 3.55$ & $155.9 \pm 19.85$ & $225.73 \pm 47.88$ \\
\hline & & $\mathrm{F}$ & & $7.3 \pm 2.80$ & $8.47 \pm 2.18$ & $127.7 \mid \pm 18.36$ & $181.0 \pm 35.43$ \\
\hline \multirow[t]{2}{*}{ Nayagam et al ${ }^{15}$} & 2014 & $\mathrm{D}$ & $4.9 \pm 0.92$ & & $12.9 \pm 3.131$ & $61.79 \pm 5.86$ & \\
\hline & & $\mathrm{F}$ & $5.1 \pm 0.82$ & & $11.8 \pm 2.156$ & $60.24 \pm 4.89$ & \\
\hline \multirow[t]{2}{*}{ Gupta et $\mathrm{al}^{16}$} & 2011 & $\mathrm{D}$ & & $11.6 \pm 1.8$ & $12.3 \pm 1.8$ & $120 \pm 22.2$ & $476 \pm 20$ \\
\hline & & $\mathrm{F}$ & & $11.2 \pm 1.3$ & $12.1 \pm 1.7$ & $76 \pm 20.3$ & $187 \pm 12.3$ \\
\hline \multirow[t]{2}{*}{ Al-Ghanem et al ${ }^{17}$} & 2009 & $\mathrm{D}$ & $7.5 \pm 7.4$ & $14.4 \pm 6.7$ & $19.34 \pm 2.87$ & & $274.8 \pm 73.4$ \\
\hline & & $\mathrm{F}$ & $7.4 \pm 3.3$ & $14.3 \pm 5.7$ & $18.39 \pm 2.46$ & & $179.5 \pm 47.4$ \\
\hline \multirow[t]{2}{*}{ Sun et $\mathrm{al}^{18}$} & 2015 & $\mathrm{D}$ & & $7.1 \pm 2.25$ & $8.10 \pm 3.55$ & $152.9 \pm 39.62$ & $211.73 \pm 51.88$ \\
\hline & & $\mathrm{F}$ & & $7.4 \pm 2.80$ & $8.47 \pm 2.18$ & || $7.7| \pm 2| .36$ & $179.0 \pm 38.83$ \\
\hline \multirow[t]{2}{*}{ Mahendru et al ${ }^{19}$} & 2013 & D & $8.3 \pm 2.4$ & $9.7 \pm 3.2$ & $10.3 \pm 3.3$ & $146.7 \pm 20.5$ & \\
\hline & & $\mathrm{F}$ & $8.6 \pm 1.5$ & $9.0 \pm 3.0$ & $9.6 \pm 2.9$ & $119.5 \pm 22.7$ & \\
\hline
\end{tabular}

Note: *Values are mean \pm standard deviation.

Abbreviations: $D$, dexmedetomidine; $F$, fentanyl.

among the results $\left(I^{2}=80 \%\right)$, and the random effect model was used for meta-analysis (Figure 4A). The result showed that there was no significant difference between the two groups (MD $=-0.28 ; 95 \%$ CI $[-1.34,0.79], P>0.05$, $\left.I^{2}=80 \%\right)$.

\section{Sensitivity analysis}

There was a study ${ }^{12}$ of spinal anesthesia with a low dose of local anesthetic (bupivacaine only $4 \mathrm{mg}$ ), which may have resulted in heterogeneity among studies, after removing the study there was no heterogeneity between the remaining

Table 3 The summary of results from individual studies

\begin{tabular}{|c|c|c|c|c|c|c|c|}
\hline$\overline{\text { Study }}$ & Year & Application & $\begin{array}{l}\text { Duration of motor } \\
\text { block (min)* }\end{array}$ & $\begin{array}{l}\text { Pain free } \\
\text { period }(\mathrm{min})^{*}\end{array}$ & $\begin{array}{l}\text { Hypotension/ } \\
\text { bradycardia" }\end{array}$ & Pruritus" & $\begin{array}{l}\text { Side } \\
\text { effects }\end{array}$ \\
\hline \multirow[t]{2}{*}{$\overline{Q i}$ et al ${ }^{6}$} & 2016 & $\mathrm{D}$ & $|46.3| \pm 40.72$ & & $0 / 3$ & 0 & 15 \\
\hline & & $\mathrm{F}$ & $80.28 \pm 41.18$ & & $0 / 2$ & 13 & 12 \\
\hline \multirow[t]{2}{*}{ Basuni and Ahmed Ezz ${ }^{12}$} & 2014 & $\mathrm{D}$ & $73.3 \pm 8.5$ & $126.6 \pm 12.9$ & $0 / 1$ & 0 & 0 \\
\hline & & $\mathrm{F}$ & $64.2 \pm 11.9$ & $70.2 \pm 8.4$ & $2 / 0$ & 0 & 0 \\
\hline \multirow[t]{2}{*}{ Suresh and Prasad ${ }^{13}$} & 2016 & $\mathrm{D}$ & $407.53 \pm \mid 8.91$ & $231.93 \pm 17.83$ & $5 / 9$ & 0 & 6 \\
\hline & & $\mathrm{F}$ & $149.37 \pm 12.00$ & $160.13 \pm 15$ & $5 / 2$ & 3 & 7 \\
\hline \multirow[t]{2}{*}{ Li et al ${ }^{14}$} & 2015 & $D$ & $128.55 \pm 28.90$ & $360.52 \pm 29.57$ & $3 / 1$ & I & 2 \\
\hline & & $\mathrm{F}$ & $130.65 \pm 29.87$ & $275.72 \pm 25.16$ & $3 / 2$ & 1 & 4 \\
\hline \multirow[t]{2}{*}{ Nayagam et al ${ }^{15}$} & 2014 & $\mathrm{D}$ & & $8.20 \pm 2.78(h)$ & & & \\
\hline & & $\mathrm{F}$ & & $6.64 \pm 2.32(h)$ & & & \\
\hline \multirow[t]{2}{*}{ Gupta et $\mathrm{al}^{16}$} & 2011 & $\mathrm{D}$ & $42 I \pm 2 I$ & $251.7 \pm 30.69$ & $3 / 1$ & 0 & 1 \\
\hline & & $\mathrm{F}$ & $149.3 \pm 18.2$ & $168.96 \pm 15.96$ & $2 / 0$ & 1 & 3 \\
\hline \multirow[t]{2}{*}{ Al-Ghanem et $\mathrm{al}^{17}$} & 2009 & $\mathrm{D}$ & $240 \pm 64$ & & $4 / 2$ & 0 & 2 \\
\hline & & $\mathrm{F}$ & $155 \pm 46$ & & $9 / 3$ & 5 & 4 \\
\hline \multirow[t]{2}{*}{ Sun et $\mathrm{al}^{18}$} & 2015 & $D$ & $128.55 \pm 28.90$ & $352.45 \pm 26.17$ & $4 / 2$ & I & 3 \\
\hline & & $\mathrm{F}$ & $130.65 \pm 29.87$ & $265.72 \pm 25.16$ & $4 / 2$ & 1 & 8 \\
\hline \multirow[t]{2}{*}{ Mahendru et al ${ }^{19}$} & 2013 & $D$ & $273.3 \pm 24.6$ & $295.5 \pm 44.3$ & $0 / 1$ & 0 & 0 \\
\hline & & $\mathrm{F}$ & $196.0 \pm 26.8$ & $235.5 \pm 38.3$ & $0 / 0$ & 4 & I \\
\hline
\end{tabular}

Notes: *Values are mean \pm standard deviation; "values are numbers.

Abbreviations: $D$, dexmedetomidine; $F$, fentanyl. 


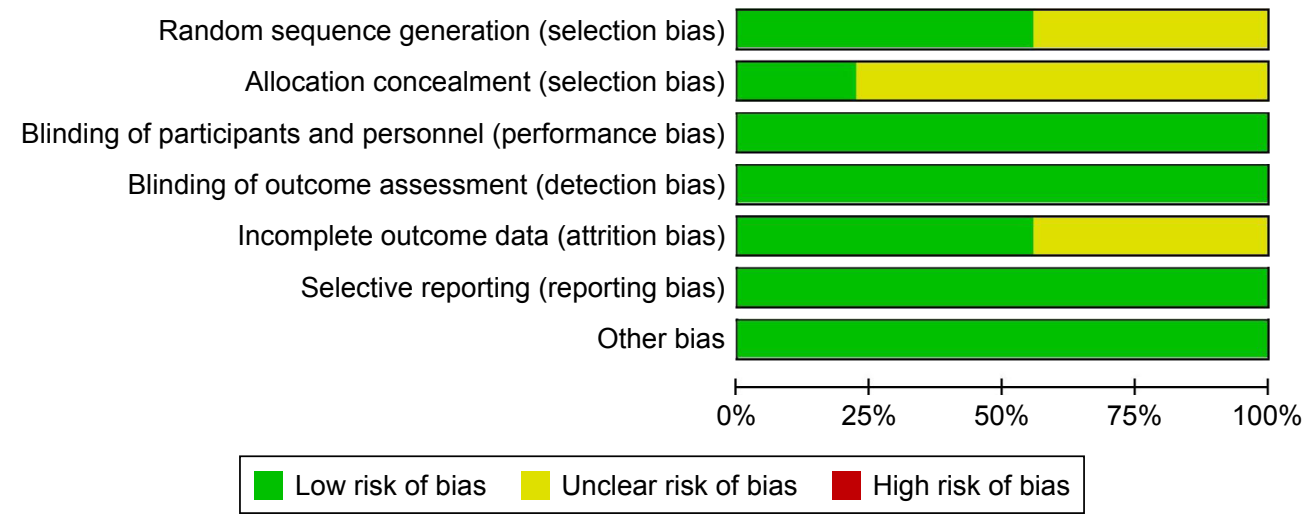

Figure $\mathbf{2}$ The risk of bias assessment of the included studies.

Note: There were no high risk of bias found in these studies.

studies $\left(I^{2}=0\right)$. Meta-analysis was performed using the fixed effect model (Figure 4B). The result showed that there was still no significant difference between the two groups $\left(\mathrm{MD}=0.3 ; 95 \% \mathrm{CI}[-0.15,0.75], P>0.05, I^{2}=0\right)$.

\section{Time to peak sensory level}

All of the included studies reported the time to peak sensory level, with 320 patients in the Dex group and 319 patients in the fentanyl group. There was moderate heterogeneity among the results $\left(I^{2}=62 \%\right)$, and the random effect model was used for meta-analysis (Figure 5). The results showed no significant difference between the two groups $(\mathrm{MD}=0.1$; $95 \%$ CI $[-0.59,0.79], P>0.05, I^{2}=62 \%$ ).

\section{Duration of stable sensory block}

Six RCTs ${ }^{13-16,18,19}$ reported the indicator of duration of stable sensory block, with high heterogeneity among the results $\left(I^{2}=97 \%\right)$, and the random effect model was used for metaanalysis (Figure 6A). The results showed that the duration of stable sensory block of the Dex group was significantly higher than the fentanyl group, the difference was statistically significant (MD $=27.12 ; 95 \%$ CI $\left.[9.89,44.34], P<0.01, I^{2}=97 \%\right)$.

\section{Sensitivity analysis}

Two of the six studies included may have led to heterogeneity among studies. One study ${ }^{15}$ used low-dose local anesthetic (4 $\mathrm{mg}$ bupivacaine) in spinal anesthesia and another ${ }^{16}$ had low quality, after removing both studies there was no heterogeneity between the remaining studies $\left(I^{2}=0\right)$. The result of meta-analysis (Figure 6B), using a fixed effect model, showed that the difference was still statistically significant $(\mathrm{MD}=28.98 ; 95 \%$ CI [24.01, 33.96], $\left.P<0.01, I^{2}=0\right)$.

\section{Duration of sensory and motor block}

Whatever the local anesthetics dose for spinal anesthesia $>10 \mathrm{mg}$ (sensory: $\mathrm{SMD}=14.93 ; 95 \%$ CI $[10.80,19.07]$, $P<0.01, I^{2}=76 \%$, motor: SMD $=10.82 ; 95 \%$ CI $[1.54$, 20.11], $P<0.05, I^{2}=98 \%$ ) or the local anesthetics dose for spinal anesthesia was $\leq 10 \mathrm{mg}$ (sensory: $\mathrm{SMD}=1.01 ; 95 \%$ CI $[0.70,1.31] P<0.01, P^{2}=39 \%$, motor: $\mathrm{SMD}=0.77 ; 95 \%$ CI $[0.06,1.48], P<0.05, I^{2}=89 \%$ ) or pooled (sensory: SMD $=3.81 ; 95 \%$ CI $[2.35,5.27] P<0.01, I^{2}=97 \%$, motor: SMD $=3.64 ; 95 \%$ CI $\left.[2.19,5.08], P<0.01, I^{2}=97 \%\right)$, Dex as an adjuvant of local anesthetics significantly prolonged the

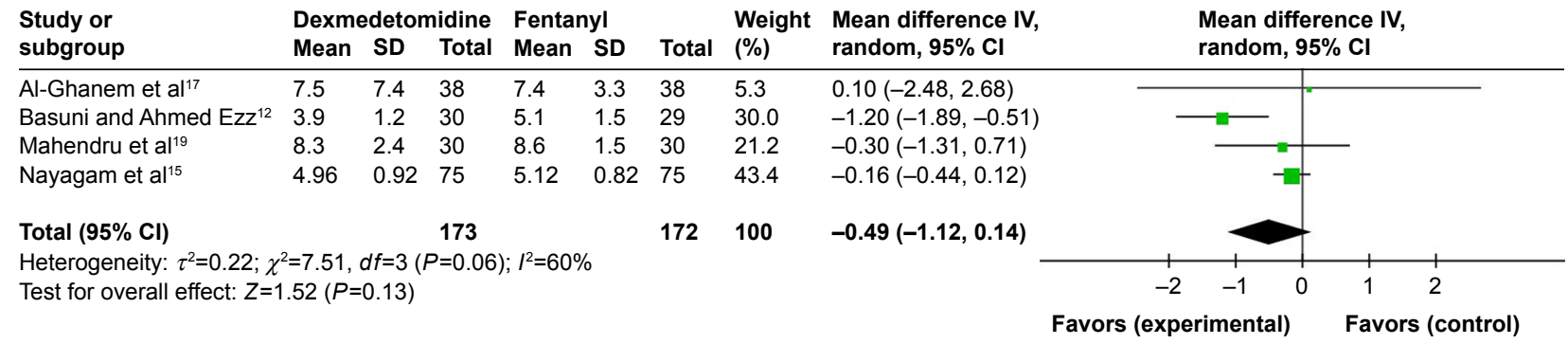

Figure 3 Forest plot for the onset of sensory block in minutes.

Abbreviations: SD, standard deviation; $\mathrm{Cl}$, confidence interval; IV, inverse variance. 


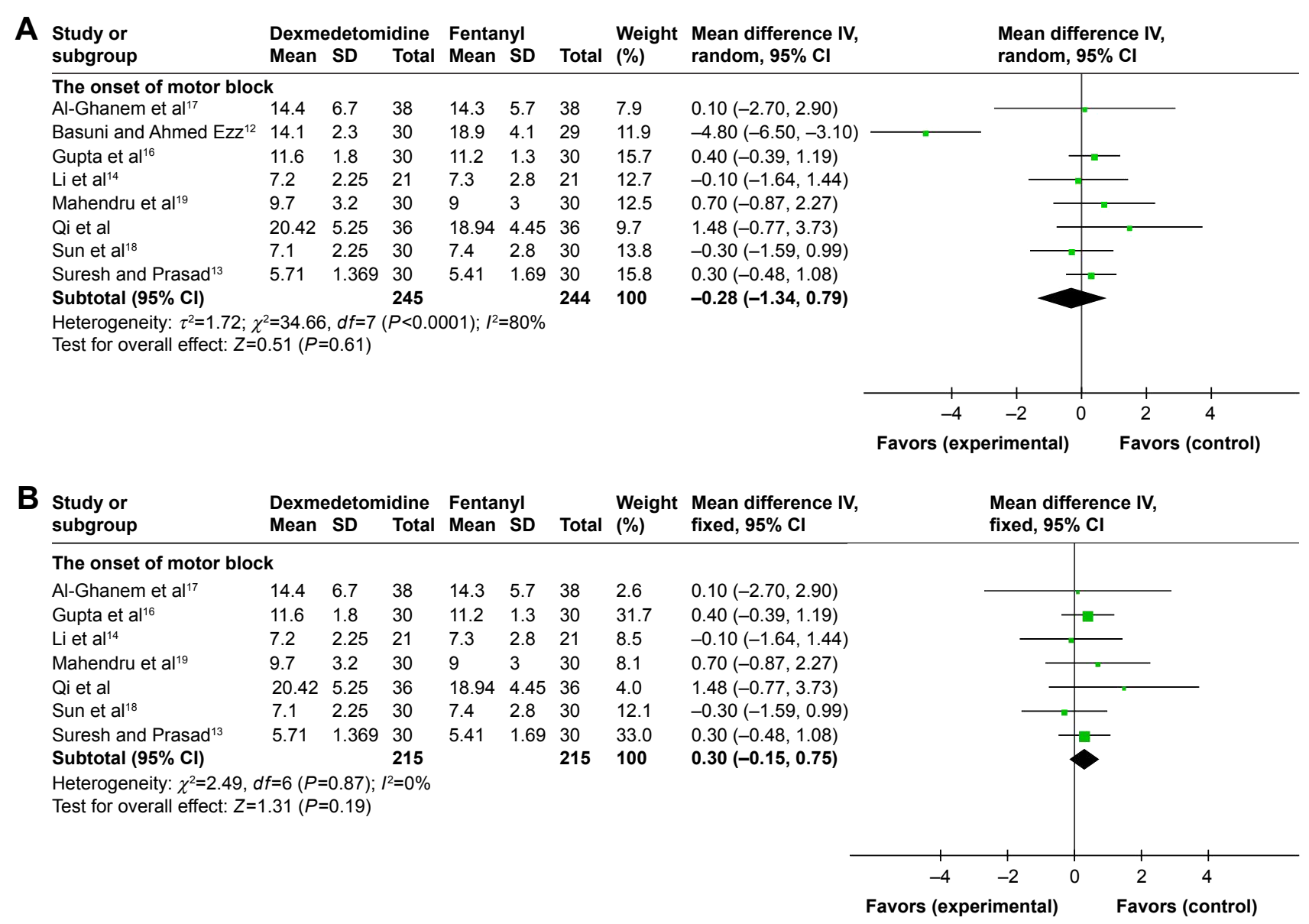

Figure 4 Forest plot for the onset of motor block in minutes $(\mathbf{A})$, forest plot for sensitivity analysis of the onset of motor block in minutes (B).

Abbreviations: SD, standard deviation; $\mathrm{Cl}$, confidence interval; IV, inverse variance.

duration of sensory and motor block compared with fentanyl. But there was significant heterogeneity in the duration of sensory $\left(I^{2}=76 \%\right)$ and motor $\left(I^{2}=98 \%\right)$ block when the local anesthetics dose for spinal anesthesia was $>10 \mathrm{mg}$, while the heterogeneity was not obvious in sensory block $\left(R^{2}=39 \%\right)$ but still significant in motor block $\left(I^{2}=89 \%\right)$ when the local anesthetics dose for spinal anesthesia was $\leq 10 \mathrm{mg}$, however, the heterogeneity of both was significant when pooled (sensory: $P^{2}=97 \%$, motor: $P^{2}=97 \%$; Figures 7 and 8 ).

\section{Pain free period}

A total of seven studies ${ }^{12-16,18,19}$ were included. The result of meta-analysis, using a random effect model, showed that the pain free period of the Dex group was significantly longer

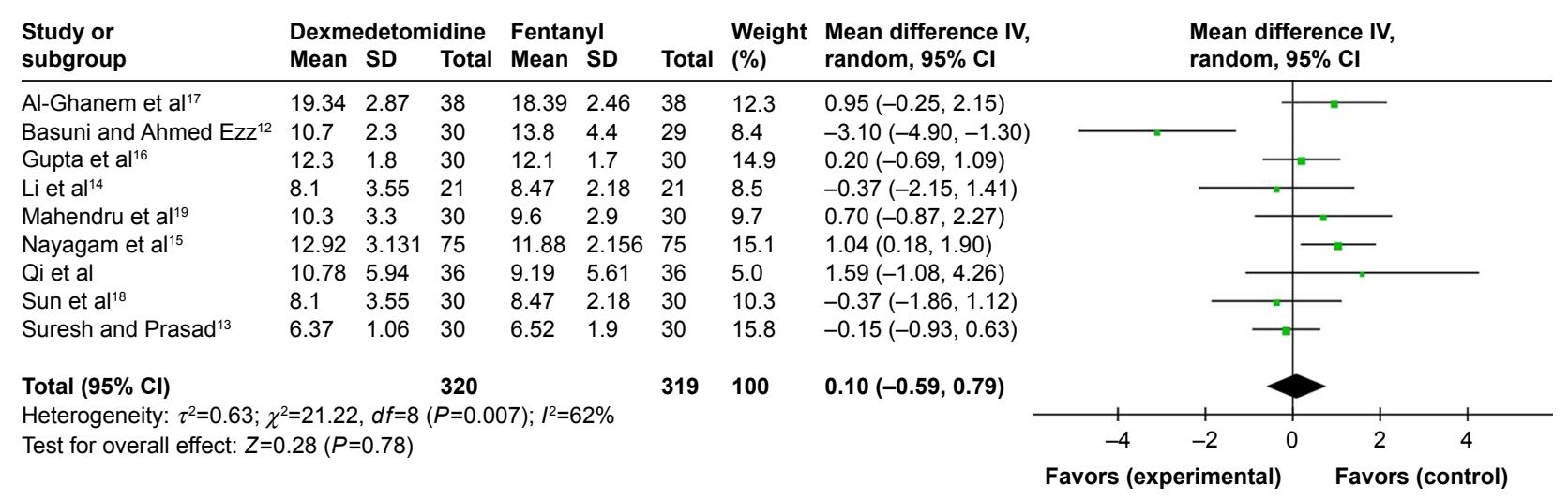

Figure 5 Forest plot for the time to peak sensory level.

Abbreviations: SD, standard deviation; Cl, confidence interval; IV, inverse variance. 
A

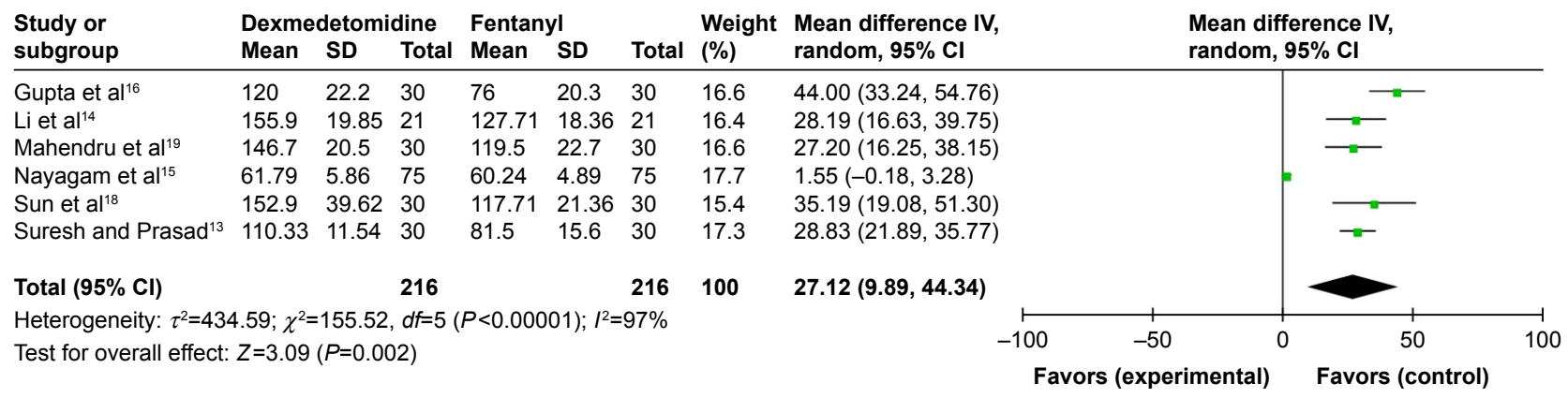

B

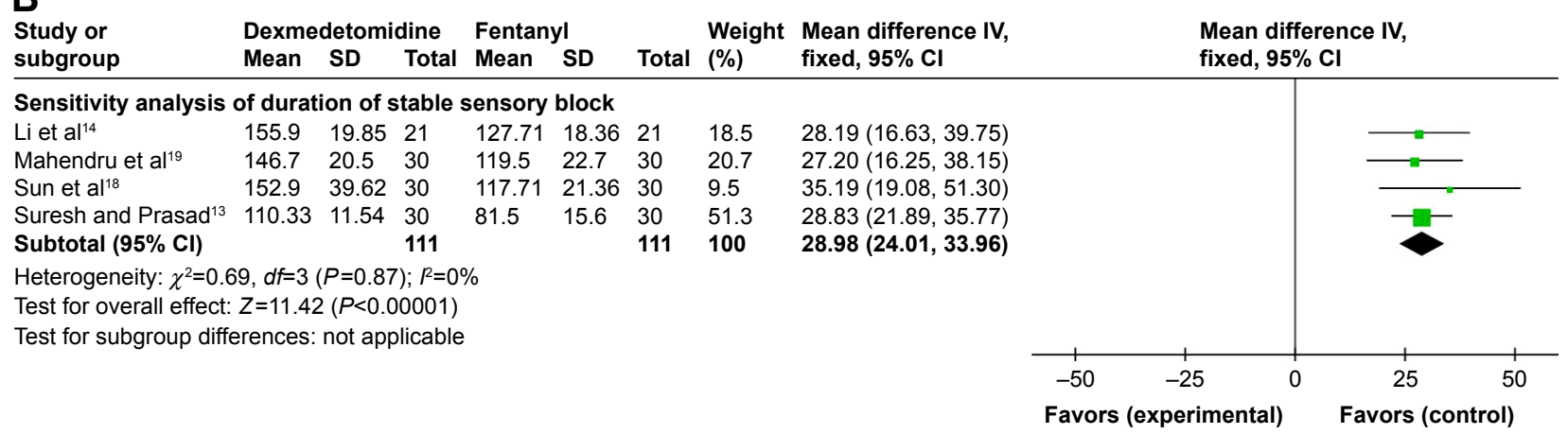

Figure 6 Forest plot for duration of stable sensory block in minutes (A), forest plot for the sensitivity analysis of duration of stable sensory block in minutes (B). Abbreviations: SD, standard deviation; $\mathrm{Cl}$, confidence interval; IV, inverse variance.

than the fentanyl group, and the difference was statistically significant, but there was high heterogeneity $(\mathrm{SMD}=2.98$; 95\% CI $[1.69,4.27], P<0.01, I^{2}=96 \%$; Figure 9A).

\section{Sensitivity analysis}

One ${ }^{19}$ of the seven studies defined the index of pain free period from spinal injection to the time of first complaint about pain, while the remaining studies used the time from intrathecal injection to the first time rescue analgesia; and the other two studies ${ }^{12,15}$ used low-dose local anesthetic (4 mg bupivacaine) in spinal anesthesia. After removing the three studies, the heterogeneity of the remaining studies was significantly reduced $\left(I^{2}=27 \%\right)$, and the fixed effect model was used for meta-analysis. The results showed that the difference

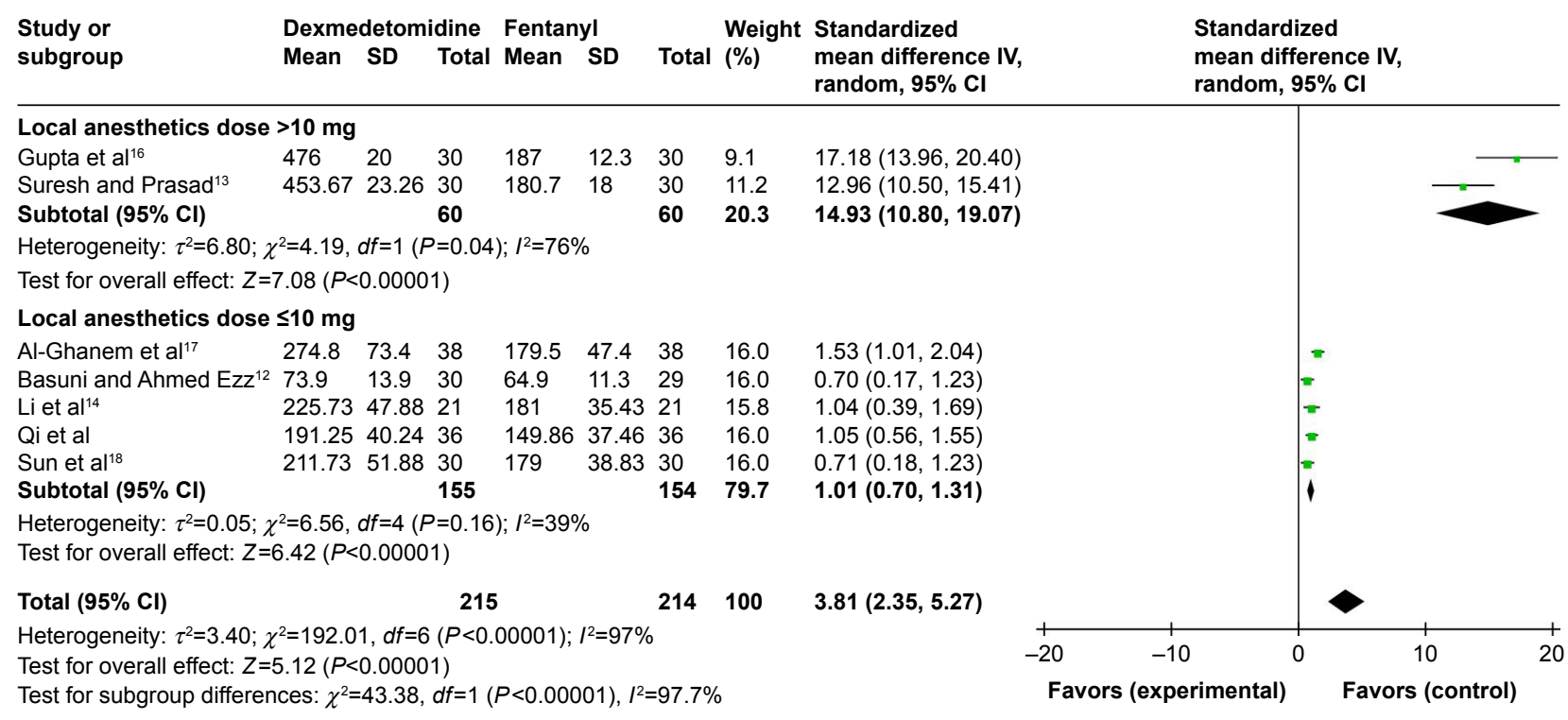

Figure 7 Forest plot for the subgroup analysis of duration of sensory block in minutes. Abbreviations: SD, standard deviation; $\mathrm{Cl}$, confidence interval; IV, inverse variance. 


\begin{tabular}{|c|c|c|c|c|c|c|c|}
\hline \multirow{2}{*}{$\begin{array}{l}\text { Study or } \\
\text { subgroup }\end{array}$} & \multicolumn{3}{|c|}{ Dexmedetomidine } & \multicolumn{3}{|c|}{ Fentanyl } & \multirow{2}{*}{$\begin{array}{l}\text { Wei } \\
(\%)\end{array}$} \\
\hline & Mean & SD & Total & Mean & SD & Total & \\
\hline \multicolumn{8}{|c|}{ Local anesthetics dose $>10 \mathrm{mg}$} \\
\hline Gupta et $\mathrm{al}^{16}$ & 421 & 21 & 30 & 149.3 & 18.2 & 30 & 9.7 \\
\hline Mahendru et al ${ }^{19}$ & 273.3 & 24.6 & 30 & 196 & 26.8 & 30 & \\
\hline Suresh and Prasad ${ }^{13}$ & 407.53 & 18.91 & 30 & 149.37 & 12 & 30 & 8.7 \\
\hline Subtotal $(95 \% \mathrm{Cl})$ & & & 90 & & & 90 & \\
\hline \multicolumn{8}{|c|}{ Heterogeneity: $\tau^{2}=65.92 ; \chi^{2}=121.16, d f=2(P<0.00001) ; I^{2}=98 \%$} \\
\hline \multicolumn{8}{|c|}{ Test for overall effect: $Z=2.28(P=0.02)$} \\
\hline \multicolumn{8}{|c|}{ Local anesthetics dose $\leq 10 \mathrm{mg}$} \\
\hline Al-Ghanem et al ${ }^{17}$ & 240 & 64 & 38 & 155 & 46 & 38 & \\
\hline Basuni and Ahmed $\mathrm{Ezz}^{12}$ & 73.3 & 8.5 & 30 & 64.2 & 11.9 & 29 & \\
\hline Li et $\mathrm{al}^{14}$ & 128.55 & 28.9 & 21 & 130.65 & 29.87 & 21 & \\
\hline Qi et al & 146.31 & 40.72 & 36 & 80.28 & 41.18 & 36 & \\
\hline Sun et $a^{18}$ & 128.55 & 28.9 & 30 & 130.65 & 29.87 & 30 & \\
\hline Subtotal $(95 \% \mathrm{Cl})$ & & & 155 & & & 154 & \\
\hline \multicolumn{8}{|c|}{ Heterogeneity: $\tau^{2}=0.59 ; \chi^{2}=35.24, d f=4(P<0.00001) ; I^{2}=89 \%$} \\
\hline \multicolumn{8}{|c|}{ Test for overall effect: $Z=2.12(P=0.03)$} \\
\hline \multirow{2}{*}{\multicolumn{6}{|c|}{$\begin{array}{l}\text { Total }(95 \% \mathrm{Cl}) \\
\text { Heterogeneity: } \tau^{2}=3.92 ; \chi^{2}=250.54, d f=7(P\end{array}$}} & 244 & \\
\hline & & & & & & & \\
\hline \multicolumn{8}{|c|}{ Test for overall effect: $Z=4.92(P<0.00001)$} \\
\hline \multicolumn{8}{|c|}{ Test for subgroup differences: $\chi^{2}=4.47, d f=1(P=0.03) ; I^{2}=77.7 \%$} \\
\hline
\end{tabular}

was still statistically significant ( $\mathrm{SMD}=3.47 ; 95 \% \mathrm{CI}[3.04$, 3.90], $P<0.01, I^{2}=27 \%$; Figure 9B).

\section{Hypotension and bradycardia}

Eight studies ${ }^{6,12-14,16-19}$ described the incidence of hypotension and bradycardia in Dex and fentanyl as local anesthetic adjuvants for intrathecal injection. There were
245 patients in the Dex group (19 with hypotension and 20 with bradycardia) and 244 patients in the fentanyl group ( 25 with hypotension and eleven with bradycardia). There was no heterogeneity among the results $\left(I^{2}=0 \%\right)$, using the fixed effect model for meta-analysis (Figure 10). The results showed the difference was not statistically significant (hypotension: RR $=0.76 ; 95 \%$ CI $[0.44,1.32]$,

A

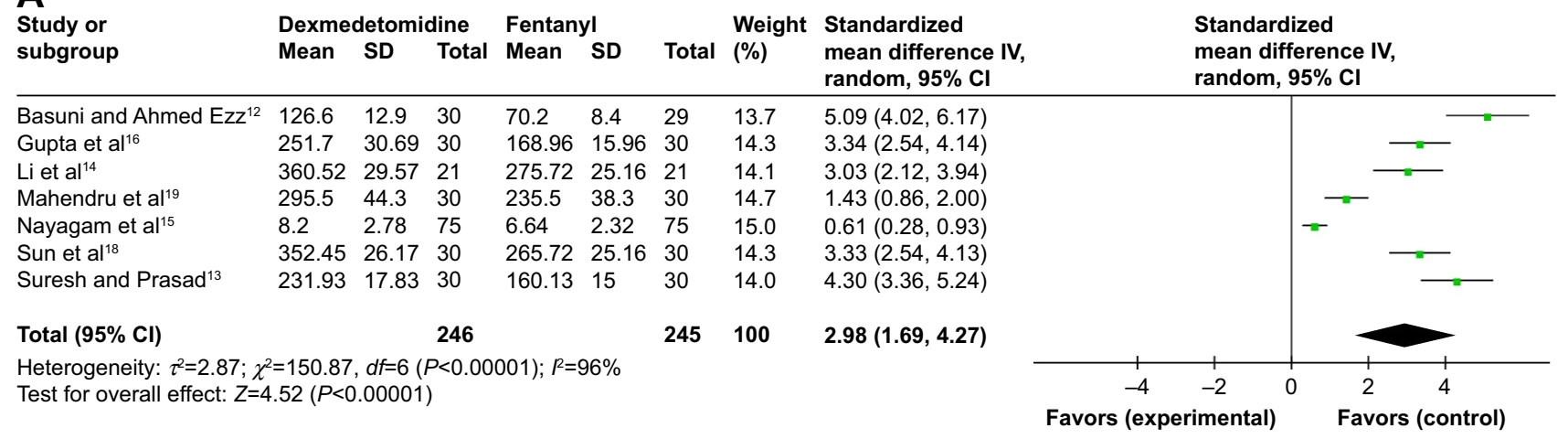

B

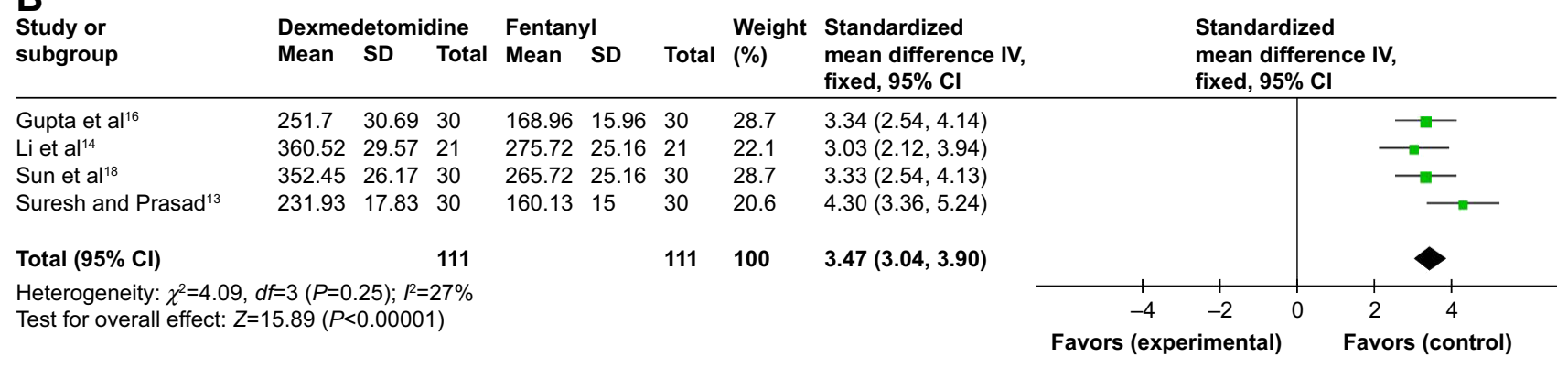

Figure 9 Forest plot for pain free period in minutes (A), forest plot for the sensitivity analysis of pain free period in minutes (B).

Abbreviations: SD, standard deviation; $\mathrm{Cl}$, confidence interval; IV, inverse variance. 


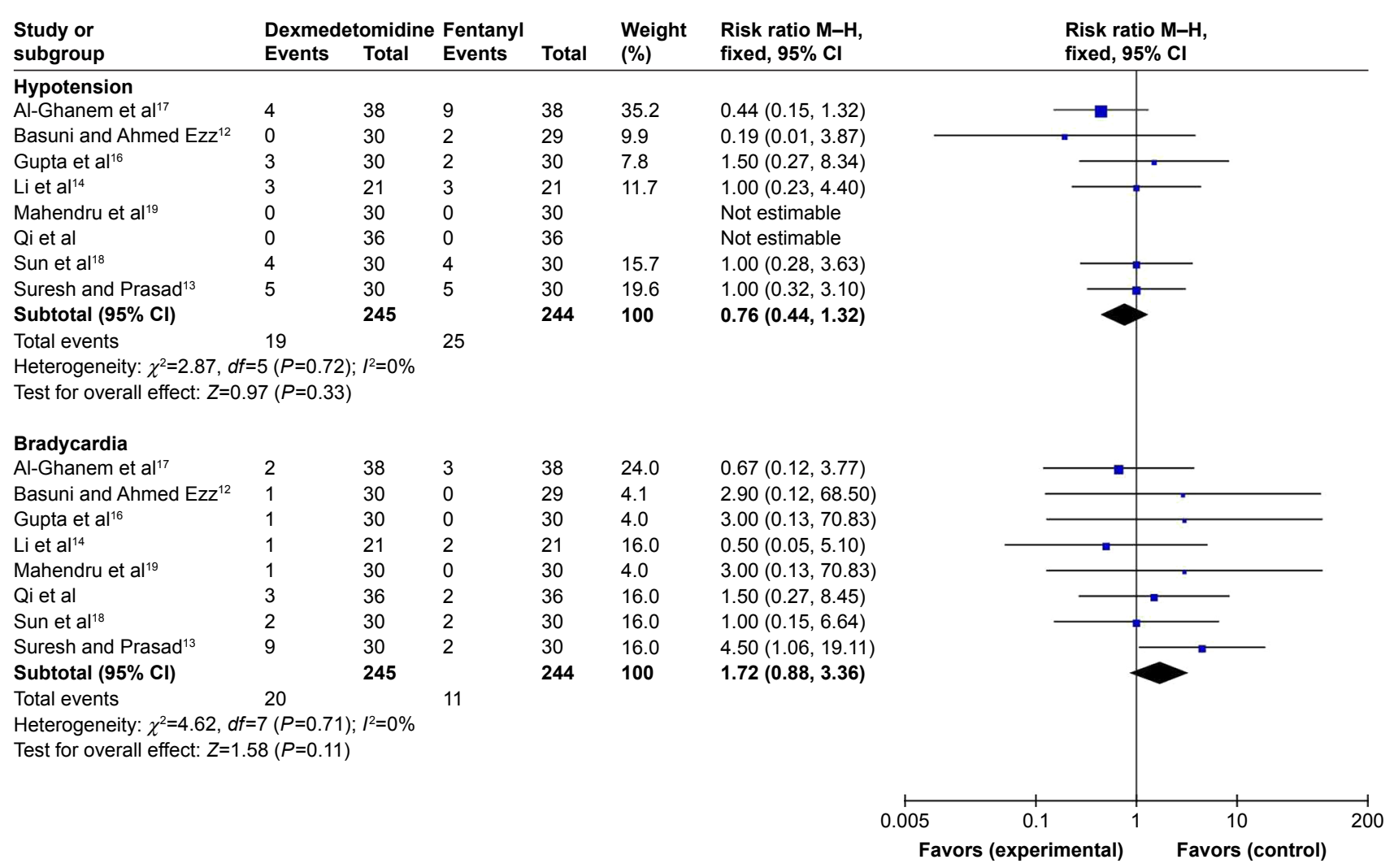

Figure 10 Forest plot comparing the incidence of hypotension and bradycardia. Abbreviations: $\mathrm{Cl}$, confidence interval; $\mathrm{M}-\mathrm{H}$, Mantel-Haenszel.

$P>0.05, I^{2}=0 \%$; bradycardia: $\mathrm{RR}=1.72 ; 95 \%$ CI $[0.88$, 3.36], $P>0.05, I^{2}=0 \%$ ).

\section{Pruritus}

There were eight studies ${ }^{6,12-14,16-19}$ reporting the incidence of pruritus, and no heterogeneity among the studies $\left(I^{2}=0 \%\right)$. The results of the meta-analysis, using the fixed effect model, showed that the incidence of pruritus in the fentanyl group was significantly higher than the Dex group, and the difference was statistically significant $(\mathrm{RR}=0.15 ; 95 \% \mathrm{CI}$ [0.06, 0.39], $P<0.01, I^{2}=0 \%$, Figure 11).

\section{The side effects}

Eight studies ${ }^{6,12-14,16-19}$ recorded the side effects, and there was no heterogeneity among the studies $\left(I^{2}=0 \%\right)$. The side effects included nausea, vomiting, shivering, and respiratory depression. The meta-analysis result of the incidence of the side effects between Dex and fentanyl group was

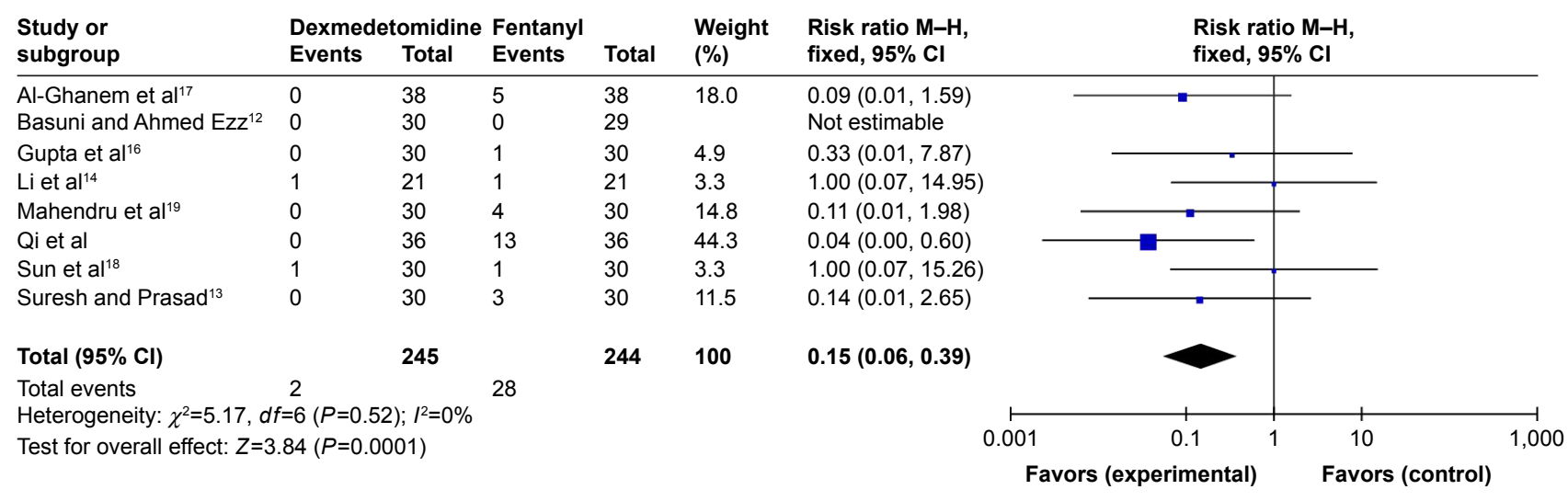

Figure I I Forest plot comparing the incidence of pruritus. Abbreviations: $\mathrm{Cl}$, confidence interval; $\mathrm{M}-\mathrm{H}$, Mantel-Haenszel. 


\begin{tabular}{|c|c|c|c|c|c|}
\hline $\begin{array}{l}\text { Study or } \\
\text { subgroup }\end{array}$ & $\begin{array}{l}\text { Dexmede } \\
\text { Events }\end{array}$ & $\begin{array}{l}\text { tomidine } \\
\text { Total }\end{array}$ & $\begin{array}{l}\text { Fentanyl } \\
\text { Events }\end{array}$ & Total & $\begin{array}{l}\text { Weight } \\
(\%)\end{array}$ \\
\hline Al-Ghanem et al ${ }^{17}$ & 2 & 38 & 4 & 38 & 10.1 \\
\hline Basuni and Ahmed Ezz ${ }^{12}$ & 0 & 30 & 0 & 29 & \\
\hline Gupta et $\mathrm{al}^{16}$ & 1 & 30 & 3 & 30 & 7.6 \\
\hline Li et al ${ }^{14}$ & 2 & 21 & 4 & 21 & 10.1 \\
\hline Mahendru et $\mathrm{al}^{19}$ & 0 & 30 & 1 & 30 & 3.8 \\
\hline Qi et al & 15 & 36 & 12 & 36 & 30.4 \\
\hline Sun et $\mathrm{al}^{18}$ & 3 & 30 & 8 & 30 & 20.3 \\
\hline Suresh and Prasad ${ }^{13}$ & 6 & 30 & 7 & 30 & 17.7 \\
\hline Total $(95 \% \mathrm{Cl})$ & & 245 & & 244 & 100 \\
\hline
\end{tabular}

\section{Total events}

29

Heterogeneity: $\chi^{2}=5.34, d f=6(P=0.50) ; I^{2}=0 \%$ 39

Test for overall effect: $Z=1.37(P=0.17)$

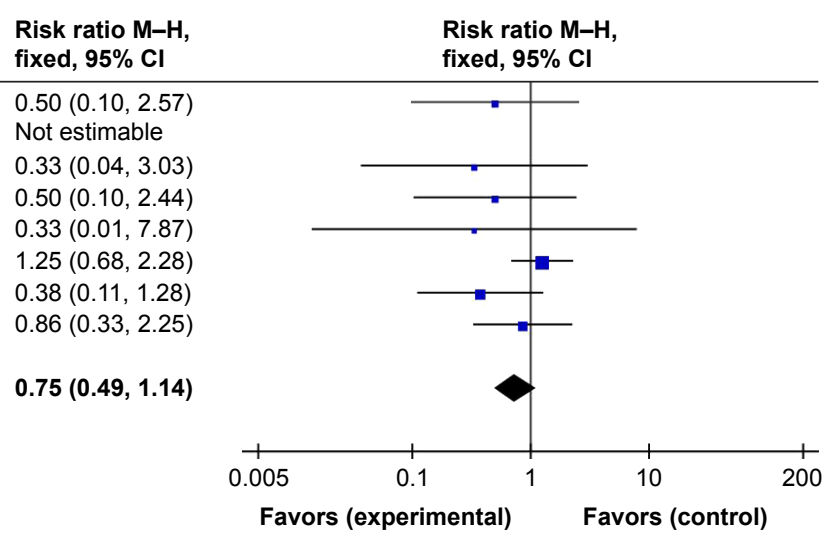

Figure 12 Forest plot comparing the incidence of side effects.

Abbreviations: $\mathrm{Cl}$, confidence interval; $\mathrm{M}-\mathrm{H}$, Mantel-Haenszel.

not statistically significant $(\mathrm{RR}=0.75 ; 95 \%$ CI $[0.49,1.14]$, $P>0.05, I^{2}=0 \%$, Figure 12 ).

\section{Discussion}

Spinal anesthesia is a common technique for lower abdomen and lower limb surgery, but the use of local anesthetics alone may produce unwanted side effects such as prolonged motor and autonomic block, limited duration of action, besides, excessive local anesthetics can cause cardiac toxicity and central nervous system side effects. ${ }^{7}$ For these reasons, local anesthetics combined with other drugs, to utilize their synergistic analgesia and to reduce the dose of local anesthetics, has become a new option for anesthesiologists. Of course, adjuvants are not necessary for spinal anesthesia and additional medical expenses of adjuvants should also be considered, moreover, adjuvants may themselves cause side effects, eg, higher doses of opioids may cause pruritus and Dex may cause bradycardia.

Opioids as an adjuvant has been the most commonly used to reduce the dose of intrathecal local anesthetics and improve the block quality, however, many of the adverse effects associated with the use of opioids plague everyone, such as urinary retention, pruritus, nausea and vomiting, and respiratory depression. ${ }^{20-22}$ It has been found that Dex prolongs the postoperative analgesia of local anesthetics with less side effects, and is a very promising adjuvant to improve the quality of spinal anesthesia. ${ }^{23-26}$ This meta-analysis was designed to evaluate the efficacy and characteristics of Dex and fentanyl as adjuvants to local anesthetics during spinal anesthesia.

In this meta-analysis, Dex significantly prolonged the duration of sensory and motor block compared with fentanyl, and had a longer pain free period and less postoperative analgesic requirements. But there was a high level of heterogeneity among these outcomes, which may be related to the following: 1) the dose and type of local anesthetics for intrathecal injection were different among studies included, meanwhile the dose of Dex and fentanyl was also different; 2) the evaluation criteria for the indicator of pain free period was different between studies - in one study it was the time from intrathecal injection to time patient first complained of pain postoperatively - while in others the first rescue analgesia was used; 3) unit of measurement for indicating pain free period was different, Nayagam et al used hours, ${ }^{15}$ while the remaining studies used minutes; 4) the type and duration of surgeries were different. Our results showed that the incidence of pruritus in the Dex group was significantly lower than in the fentanyl group, but there was no significant difference in the incidence of other side effects (nausea, vomiting, shivering, or respiratory depression).

Coombs et $\mathrm{al}^{27}$ first introduced the analgesic properties of $\alpha_{2}$ adrenergic receptor agonists during intrathecal injection. Subsequent studies have shown that the abirritation of intrathecal $\alpha_{2}$-adrenoreceptor agonists is mainly achieved by inhibiting the release of $\mathrm{C}$-fiber transmitters and substance $\mathrm{P}$, and hyperpolarizing post-synaptic dorsal horn neurons, ${ }^{20,28,29}$ and the analgesic effect has a good correlation with their binding affinity to the spinal $\alpha_{2}$ adrenergic receptors. ${ }^{30}$ Therefore, Dex as a highly selective $\alpha_{2}$-adrenoreceptor agonist $\left(\alpha_{2} / \alpha_{1} 1,600: 1\right)$, has greater advantages than clonidine in intrathecal injection for analgesia.

The greatest concern about the intrathecal application of Dex is its neurotoxicity. It managed to cause moderate to severe demyelination of white matter when it was administered by epidural route at a dose of up to $6.1 \mu \mathrm{g} \cdot \mathrm{kg}^{-1}$ in rabbits. ${ }^{31}$ However, in an experiment with sheep, Dex $(2.5-100 \mu \mathrm{g})$ intrathecal injection did not cause neurological deficits. ${ }^{32}$ In the systematic review by Abdallah and Brull, ${ }^{2}$ 
doses of Dex up to $0.2 \mu \mathrm{g} \cdot \mathrm{kg}^{-1}$ for intrathecal and $1 \mu \mathrm{g} \cdot \mathrm{kg}^{-1}$ for peripheral administration did not produce any neurotoxic manifestations, of course, the conclusion was based on isolated small animal data. Three of the studies reported the results of neurological deficits secondary to spinal anesthesia: no patients had neurological impairment within 1 week postoperatively in Gupta et al's study; ${ }^{16}$ during 48-hour postoperative follow-up, there was a case of post-dural puncture headache in the fentanyl group, and a case of transient nerve syndrome in the Dex group, but both were transient, not severe, and did not need additional treatment; ${ }^{6}$ Al-Ghanem et $\mathrm{al}^{17}$ reported two patients with postdural puncture headache, but they were in the fentanyl group. At present, most of the data have shown that Dex intrathecal application did not appear very severe neurotoxicity performance on human in the short term, ${ }^{33,34}$ but the data of long-term neurotoxicity performance are absent.

There are some limitations in our meta-analysis. First, it is possible we have missed some studies that satisfied the inclusion criteria, and some studies had to be excluded as the full text was unavailable. Second, there was significant heterogeneity regarding the duration of sensory and motor block, and pain free period, as there were different intrathecal drugs (bupivacaine, ropivacaine), different doses of drugs, and different evaluation criteria and types of surgery. Third, Dex intrathecal application caused delayed recovery of motor power whether there is practical clinical significance, such as venous thrombosis of lower limbs, prolonged hospitalization, and whether Dex combined with low-dose local anesthetics can eliminate these drawbacks, we did not analyze due to lack of research data. However, these questions are very meaningful research points for the future.

In summary, when compared to fentanyl, we found that Dex, as adjuvant to local anesthetics for intrathecal injection, can statistically significantly prolong the duration of sensory and motor block, as well as the pain free period, meanwhile significantly reducing the incidence of pruritus without increasing the risk of hypotension and bradycardia.

\section{Disclosure}

The authors report no conflicts of interest in this work.

\section{References}

1. Boublik J, Gupta R, Bhar S, Atchabahian A. Prilocaine spinal anesthesia for ambulatory surgery: A review of the available studies. Anaesth Crit Care Pain Med. 2016;35(6):417-421.

2. Abdallah FW, Brull R. Facilitatory effects of perineural dexmedetomidine on neuraxial and peripheral nerve block: a systematic review and metaanalysis. Br J Anaesth. 2013;110(6):915-925.
3. Sapate M, Sahu P, Thatte WS, Dubey R. A randomized, double blind, control study of the effects of adding nalbuphine to spinal bupivacaine for lower abdominal surgeries in elderly patients. Anaesthesia, Pain \& Intensive Care. 2013;17(2):145-148.

4. Chung F, Mezei G. Factors contributing to a prolonged stay after ambulatory surgery. Anesth Analg. 1999;89(6):1352-1359.

5. Dyer RA, Joubert IA. Low-dose spinal anaesthesia for caesarean section. Curr Opin Anaesthesiol. 2004;17(4):301-308.

6. Qi X, Li Y, Rahe-Meyer N, et al. Intrathecal dexmedetomidine as adjuvant to ropivacaine in hysteroscopic surgery: a prospective, randomized control study. Int J Clin Pharmacol Ther. 2016;54(3): 185-192.

7. Marri SR. Adjuvant agents in regional anaesthesia. Anaesthesia and Intensive Care Medicine. 2012;13(11):559-562.

8. Zhang C, Li C, Pirrone M, Sun L, Mi W. Comparison of dexmedetomidine and clonidine as adjuvants to local anesthetics for intrathecal anesthesia: a meta-analysis of randomized controlled trials. J Clin Pharmacol. 2016;56(7):827-834.

9. Gupta R, Bogra J, Verma R, Kohli M, Kushwaha JK, Kumar S. Dexmedetomidine as an intrathecal adjuvant for postoperative analgesia. Indian J Anaesth. 2011;55(4):347-351.

10. Al-Mustafa MM, Abu-Halaweh SA, Aloweidi AS, et al. Effect of dexmedetomidine added to spinal bupivacaine for urological procedures. Saudi Med J. 2009;30(3):365-370.

11. Owen MD, Ozsaraç O, Sahin S, Uçkunkaya N, Kaplan N, Magunaci I. Low-dose clonidine and neostigmine prolong the duration of intrathecal bupivacaine-fentanyl for labor analgesia. Anesthesiology. 2000; 92(2):361-366.

12. Basuni AS, Ahmed Ezz HA. Dexmedetomidine as supplement to lowdose levobupivacaine spinal anesthesia for knee arthroscopy. Egyptian Journal of Anaesthesia. 2014;30(2):149-153.

13. Suresh G, Prasad CG. A comparative study of intrathecal $0.5 \%$ hyperbaric bupivacaine with dexmedetomidine and $0.5 \%$ hyperbaric bupivacaine with fentanyl for lower abdominal surgeries. Sri Lankan Journal of Anaesthesiology. 2016;24(1):22-27.

14. Li Z, Tian M, Zhang CY, et al. A randomised controlled trial to evaluate the effectiveness of intrathecal bupivacaine combined with different adjuvants (fentanyl, clonidine and dexmedetomidine) in caesarean section. Drug Res (Stuttg). 2015;65(11):581-586.

15. Nayagam HA, Singh NR, Singh HS. A prospective randomised double blind study of intrathecal fentanyl and dexmedetomidine added to low dose bupivacaine for spinal anesthesia for lower abdominal surgeries. Indian J Anaesth. 2014;58(4):430-435.

16. Gupta R, Verma R, Bogra J, Kohli M, Raman R, Kushwaha JK. A Comparative study of intrathecal dexmedetomidine and fentanyl as adjuvants to Bupivacaine. J Anaesthesiol Clin Pharmacol. 2011;27(3): 339-343.

17. Al-Ghanem SM, Massad IM, Al-Mustafa MM, et al. Effect of adding dexmedetomidine versus fentanyl to intrathecal bupivacaine on spinal block characteristics in gynecological procedures: a double blind controlled study. American Journal of Applied Sciences. 2009;6(5): 882-887.

18. Sun Y, Xu Y, Wang GN. Comparative evaluation of intrathecal bupivacaine alone, bupivacaine-fentanyl, and bupivacaine-dexmedetomidine in caesarean section. Drug Res (Stuttg). 2015;65(9):468-472.

19. Mahendru V, Tewari A, Katyal S, Grewal A, Singh MR, Katyal R. A comparison of intrathecal dexmedetomidine, clonidine, and fentanyl as adjuvants to hyperbaric bupivacaine for lower limb surgery: a double blind controlled study. J Anaesthesiol Clin Pharmacol. 2013;29(4): 496-502.

20. Kim JE, Kim NY, Lee HS, Kil HK. Effects of intrathecal dexmedetomidine on low-dose bupivacaine spinal anesthesia in elderly patients undergoing transurethral prostatectomy. Biol Pharm Bull. 2013;36(6): 959-965.

21. Akcaboy EY, Akcaboy ZN, Gogus N. Low dose levobupivacaine $0.5 \%$ with fentanyl in spinal anaesthesia for transurethral resection of prostate surgery. J Res Med Sci. 2011;16(1):68-73. 
22. Erdil F, Bulut S, Demirbilek S, Gedik E, Gulhas N, Ersoy MO. The effects of intrathecal levobupivacaine and bupivacaine in the elderly. Anaesthesia. 2009;64(9):942-946.

23. Samantaray A, Hemanth N, Gunnampati K, Pasupuleti H, Mukkara M, Rao MH. Comparison of the effects of adding dexmedetomidine versus midazolam to intrathecal bupivacaine on postoperative analgesia. Pain Physician. 2015;18(1):71-77.

24. Qi X, Chen D, Li G, Huang X, Li Y, Wang X, Li Y. Comparison of intrathecal dexmedetomidine with morphine as adjuvants in cesarean sections. Biol Pharm Bull. 2016;39(9):1455-1460.

25. Shukla U, Prabhakar T, Malhotra K, Srivastava D. Dexmedetomidine versus midazolam as adjuvants to intrathecal bupivacaine: a clinical comparison. J Anaesthesiol Clin Pharmacol. 2016;32(2):214-219.

26. Halder S, Das A, Mandal D, et al. Effect of different doses of dexmedetomidine as adjuvant in bupivacaine-induced subarachnoid block for traumatized lower limb orthopaedic surgery: a prospective, doubleblinded and randomized controlled study. J Clin Diagn Res. 2014; 8(11):GC01-GC06.

27. Coombs DW, Saunders RL, Lachance D, Savage S, Ragnarsson TS, Jensen LE. Intrathecal morphine tolerance: use of intrathecal clonidine, DADLE, and intraventricular morphine. Anesthesiology. 1985;62(3): 358-363.

28. Lawhead RG, Blaxall HS, Bylund DB. Alpha-2A is the predominant alpha-2 adrenergic receptor subtype in human spinal cord. Anesthesiology. 1992;77(5):983-991.
29. Smith C, Birnbaum G, Carter JL, Greenstein J, Lublin FD. Tizanidine treatment of spasticity caused by multiple sclerosis: results of a doubleblind, placebo-controlled trial. US Tizanidine Study Group. Neurology. 1994;44(11 Suppl 9):S34-S42.

30. Asano T, Dohi S, Ohta S, Shimonaka H, Iida H. Antinociception by epidural and systemic alpha(2)-adrenoceptor agonists and their binding affinity in rat spinal cord and brain. Anesth Analg. 2000;90(2): 400-407.

31. Konakci S, Adanir T, Yilmaz G, Rezanko T. The efficacy and neurotoxicity of dexmedetomidine administered via the epidural route. Eur J Anaesthesiol. 2008;25(5):403-409.

32. Eisenach JC, Shafer SL, Bucklin BA, Jackson C, Kallio A. Pharmacokinetics and pharmacodynamics of intraspinal dexmedetomidine in sheep. Anesthesiology. 1994;80(6):1349-1359.

33. Kanazi GE, Aouad MT, Jabbour-Khoury SI, et al. Effect of low-dose dexmedetomidine or clonidine on the characteristics of bupivacaine spinal block. Acta Anaesthesiol Scand. 2006;50(2):222-227.

34. Hong JY, Kim WO, Yoon Y, Choi Y, Kim SH, Kil HK. Effects of intravenous dexmedetomidine on low-dose bupivacaine spinal anaesthesia in elderly patients. Acta Anaesthesiol Scand. 2012;56(3):382-387.
Drug Design, Development and Therapy

\section{Publish your work in this journal}

Drug Design, Development and Therapy is an international, peerreviewed open-access journal that spans the spectrum of drug design and development through to clinical applications. Clinical outcomes, patient safety, and programs for the development and effective, safe, and sustained use of medicines are the features of the journal, which

\section{Dovepress}

has also been accepted for indexing on PubMed Central. The manuscript management system is completely online and includes a very quick and fair peer-review system, which is all easy to use. Visit http://www.dovepress.com/testimonials.php to read real quotes from published authors.

Submit your manuscript here: http://www.dovepress.com/drug-design-development-and-therapy-journal 